\title{
Impact of Near-Field, Deep-Ocean Tsunami Observations on Forecasting the 7 December 2012 Japanese Tsunami
}

\author{
Eddie Bernard, ${ }^{1}$ Yong Wei, ${ }^{1,2}$ Liujuan Tang, ${ }^{1,2}$ and Vasily Titov ${ }^{1}$
}

\begin{abstract}
Following the devastating 11 March 2011 tsunami, two deep-ocean assessment and reporting of tsunamis (DART ${ }^{\circledR}$ ) $\left(\right.$ DART $^{\circledR}$ and the DART ${ }^{\circledR} \log$ o are registered trademarks of the National Oceanic and Atmospheric Administration, used with permission) stations were deployed in Japanese waters by the Japanese Meteorological Agency. Two weeks after deployment, on 7 December 2012, a $M_{\mathrm{w}} 7.3$ earthquake off Japan's Pacific coastline generated a tsunami. The tsunami was recorded at the two Japanese DARTs as early as $11 \mathrm{~min}$ after the earthquake origin time, which set a record as the fastest tsunami detecting time at a DART station. These data, along with those recorded at other DARTs, were used to derive a tsunami source using the National Oceanic and Atmospheric Administration tsunami forecast system. The results of our analysis show that data provided by the two nearfield Japanese DARTs can not only improve the forecast speed but also the forecast accuracy at the Japanese tide gauge stations. This study provides important guidelines for early detection and forecasting of local tsunamis.
\end{abstract}

\section{Introduction}

Following the devastating 11 March 2011 Japanese tsunami, two papers by NOAA scientists were published: (1) far-field forecast and impact of the tsunami on the Pacific basin (TANG et al. 2012) and (2) the local impact on Japan (WeI et al. 2013). Both of these studies used the "method of splitting tsunami" model that has been previously validated and verified (SYNOLAKIS et al. 2008). For the far-field study, a methodology was presented for determining the energy of a tsunami using real-time, deep-ocean assessment and reporting of tsunamis $\left(\mathrm{DART}^{\circledR}\right)$ data

\footnotetext{
1 Pacific Marine Environmental Laboratory, NOAA Center for Tsunami Research, National Oceanic and Atmospheric Administration, 7600 Sand Point Way NE, Seattle, WA 98115, USA. E-mail: eddie.bernard@comcast.net

2 Joint Institute for the Study of the Atmosphere and Ocean, University of Washington, Box 355672, Seattle, WA 98105, USA.
}

within the NOAA tsunami forecast system (TANG et al. 2012). Results of this study showed that data from DART stations, near the tsunami-generation region, could help to accurately estimate the energy of a tsunami. For the local study, nested tsunami inundation models were developed that used the source information from TANG et al.'s (2012) far-field study as input to simulate the flooding along Japan's coastline. The modeling results for tsunami inundation in the near-field along $600 \mathrm{~km}$ of Japan's coastline were compared with observed tsunami time series, surveyed tsunami height and run-up, and the extent of tsunami inundation (WEI et al. 2013). This comparison indicated inundation-modeling accuracy was approximately $85.5 \%$ for the affected area between latitudes $36-41^{\circ} \mathrm{N}$ of Japan's coastline.

Based, in part, on the forecast value of deep-ocean tsunami measurements in tsunami warnings, the Japanese Meteorological Agency (JMA), which operates the Japanese tsunami warning system, decided to install deep-ocean tsunami detection (DART) stations in Japanese waters. Two DART stations ${ }^{1}$ were deployed at locations JP1 and JP2 (see Fig. 1), on November 23 and 24, 2012 respectively. Standard performance checks for pressure accuracy and two-way communications were conducted to verify that both stations were performing as designed. The initial performance checks indicated that both Japanese DART stations were working properly in sensing and reporting pressure changes to JMA on 7 December 2012. The 7 December 2012 tsunami was recorded at both DART stations JP2 and JP1 about 11-20 min tsunami travel time from the source.

1 Produced by Science Applications International Corporation (SAIC) using DART ${ }^{\circledR}$ Technology. 


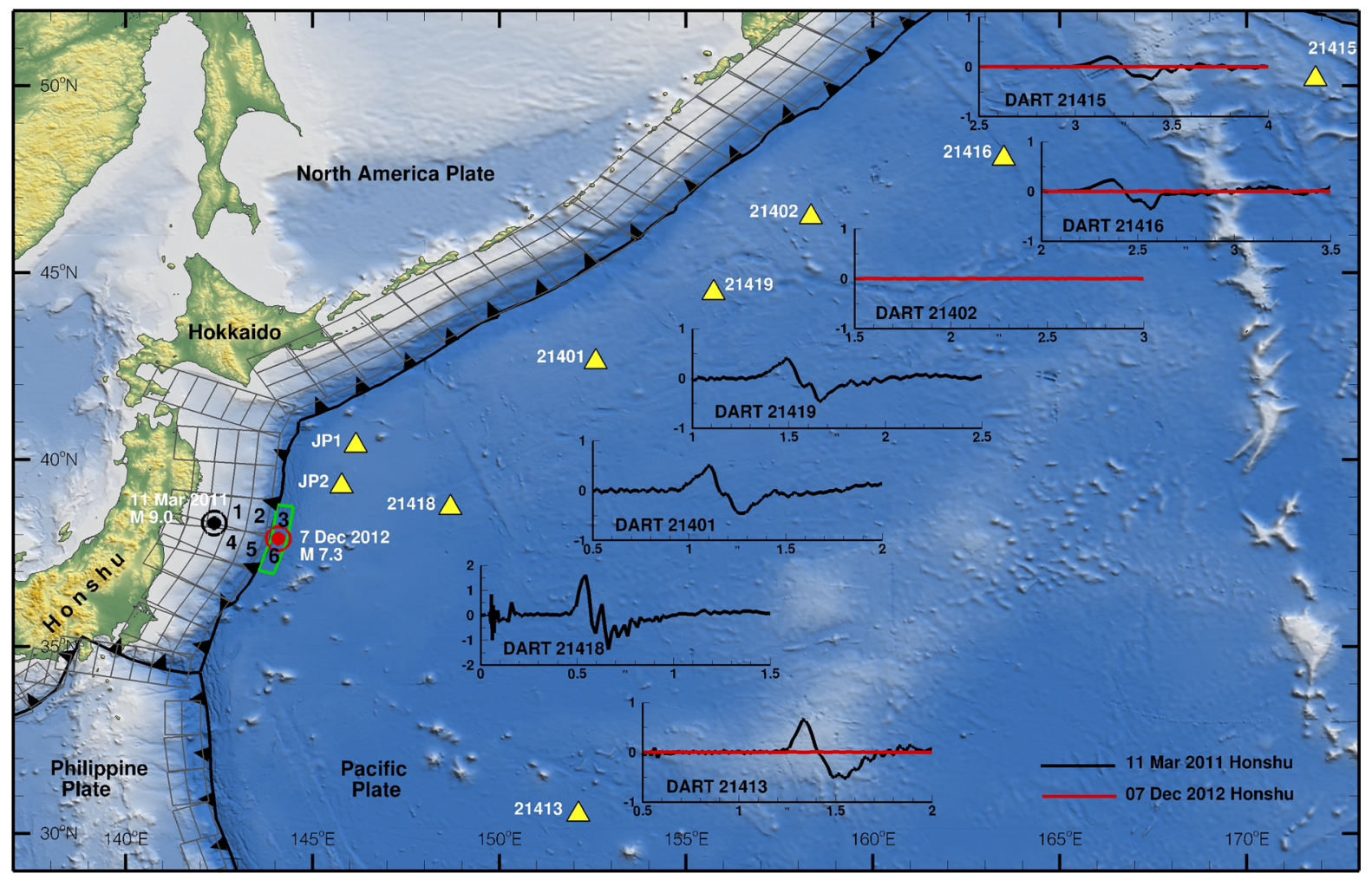

Figure 1

Locations of 6 DART stations (yellow triangles) that recorded the tsunami from the 7 December 2012 earthquake (red circle). JP1 and JP2 are Japanese-owned DART stations; 21413, 21416, and 21415 are US-owned DART stations; 21402 is a Russian-owned DART station. For comparison with the March 11, 2011 tsunami (earthquake epicenter is black circle), the tsunami time series plot adjacent to stations shows the tsunami for 2011 as a black line and for the 2012 tsunami as a red line. Note that DART station 21402 was deployed after the 2011 tsunami, hence no black line. Stations 21419, 21418 and 21401 were not operational on 7 December 2012. The gray boxes represent the unit tsunami

sources, and the two green boxes are normal-faults unit sources that were developed specifically for the 7 December 2012 tsunami

Tsunami data from JP1 and JP2 were reported in real time to JMA. However, because the two Japanese DART stations were being tested for performance acceptance, no data from JP1 or JP2 were available through NOAA in real-time.

The existing DART network near Japan, consisting of DART stations owned by the United States and Russia (see Fig. 1), was not completely operational. The two DART stations closest to the 2011 tsunami source, namely DART stations 21418 (US) and 21401 (Russia), were not operational on 7 December 2012. However, US and Russian DART stations, namely $21413,21415,21416$, and 21402 , located to the southeast and northeast of the earthquake epicenter (see Fig. 1), were operational on 7 December 2102. In summary, six DART stations in the region of Japan, owned and operated by Japan, Russia, and the
US, provided valuable measurements for us to constrain the tsunami source of the 7 December 2012 event.

\section{The Tsunami Source of 7 December 2012 Earthquake}

According to the USGS, the 7 December $2012 M_{\mathrm{w}}$ 7.3 earthquake east of Sendai, Japan occurred as a result of reverse faulting within the oceanic lithosphere of the Pacific plate, approximately $20 \mathrm{~km}$ east of the plate boundary between the Pacific and North America plates where three Pacific plates subduct beneath Japan (see Fig. 1). At the epicenter of this earthquake, the Pacific plate moves west-northwestward with respect to the North America plate at a 
Table 1

Tsunami forecast sources constrained from 4-DARTs and 6-DARTs

\begin{tabular}{llrllccc}
\hline Unit sources & Location & Strike & Dip & Rake & Depth $(\mathrm{km})$ & $\begin{array}{l}\text { Source 1 } \\
\text { 4-DART constrained } \\
\text { coefficient (m) }\end{array}$ & $\begin{array}{l}\text { Source 2 } \\
\text { 6-DART constrained } \\
\text { coefficient (m) }\end{array}$ \\
\hline 1 & & & & & & 0.2 & - \\
2 & $142.7622 \mathrm{E}, 38.5837 \mathrm{~N}$ & 188 & 21 & 90 & 21.28 & - & - \\
3 & $143.2930 \mathrm{E}, 38.5254 \mathrm{~N}$ & 188 & 19 & 90 & 5.0 & - & -0.1 \\
4 & $144.4149 \mathrm{E}, 38.2976 \mathrm{~N}$ & 8 & 40 & 90 & 5 & -0.3 & -0.4 \\
5 & $142.5320 \mathrm{E}, 37.7830 \mathrm{~N}$ & 198 & 21 & 90 & 21.28 & 0.2 & 0.1 \\
6 & $143.0357 \mathrm{E}, 37.6534 \mathrm{~N}$ & 198 & 19 & 90 & 5.0 & - & 5.0 \\
\hline
\end{tabular}

Each unit source is identified in Fig. 1 by rectangles and has a dimension of $100 \mathrm{~km}$ in length and $50 \mathrm{~km}$ in width. Positive coefficients for each source indicates a thrust fault movement, while negative coefficients indicates a normal fault movement

velocity of approximately $83 \mathrm{~mm} /$ year (http:// earthquake.usgs.gov/earthquakes/map/). The Harvard Centroid Moment Tensor (CMT) project reported two earthquakes, the first, a thrust fault earthquake of $M_{\mathrm{w}} 7.2$, followed $12 \mathrm{~s}$ later by a normal fault earthquake of equal magnitude approximately at the same location (http://www.globalcmt.org/).

A tsunami source was computed based on the real-time deep-ocean tsunami observations recorded at the four DARTs (source 1 in Table 1). Figure $2 \mathrm{a}-\mathrm{d}$ (green line) show good model-data comparison at the four stations. However, at the two near-field Japanese DARTs, the modeled wave period is too long (Fig. 2e, f).

By using the Japanese retrospective DART data in addition to the data from the other four stations, a second source was derived (source 2 in Table 1). A good solution was found when the model time series were shifted 2 min behind (red line in Fig. 2). It should be noted each unit source has a spatial resolution of 100 by $50 \mathrm{~km}$. If an earthquake occurs in between of two adjacent unit sources, the model could introduce a travel time error of 2-4 min, depending on the orientation and water depth. Figure 2 shows that the 6-DART source (red line) gives an improved fit to the observations, particularly the period and amplitude of the first wave at the two Japanese DART stations.

Table 1 summarizes the source parameters and coefficients for the 4- and 6-DART inverted sources. A positive source coefficient implies an initial tsunami triggered by a thrust fault rupture, while a negative coefficient indicates the cause of a normal- fault rupture. Clearly, the source coefficients obtained through both inversions indicate the complexity of the 7 December 2012 event that involved both normal- and thrust-fault ruptures, as indicated by the CMT solutions.

Development in processing technology and the availability of robust seismic measurements have identified multiple source mechanisms in recent tsunamis. For example, the 29 September 2009 Samoa tsunami was caused by a $M 8.1$ normal faulting in the outer trench followed by two M7.8 under thrusting sub events (LAY et al. 2010), or thrust-fault triggered outer-rise earthquake (BEAVAN et al. 2010). The 12 January 2010 Haiti tsunami may have been generated by complex rupture from both strike-slip and thrust faults (Hayes et al. 2011; CAlAis et al. 2011). In addition, the 11 March 2011 Japan tsunami may have even involved contribution from a seabed failure that was responsible for the high run-up along Sanriku's coasts (GRILLI et al. 2012). At present, these earthquake complexities are hard to identify until rigorous, post-event, seismic analysis is performed. However, these complex earthquake processes that produce tsunamis are reflected in the tsunami wave measurements, and can be estimated through inversion of the recorded tsunami time series in real-time (TiTov 2009; Wei et al. 2008). The advantage of DARTinversion allows the models to capture the characteristics of the tsunami, including its energy content, in real time necessary for effective warnings (TANG et al. 2012).

Figure 3 illustrates the tsunami maximum offshore amplitude for the 6-DART tsunami source that 

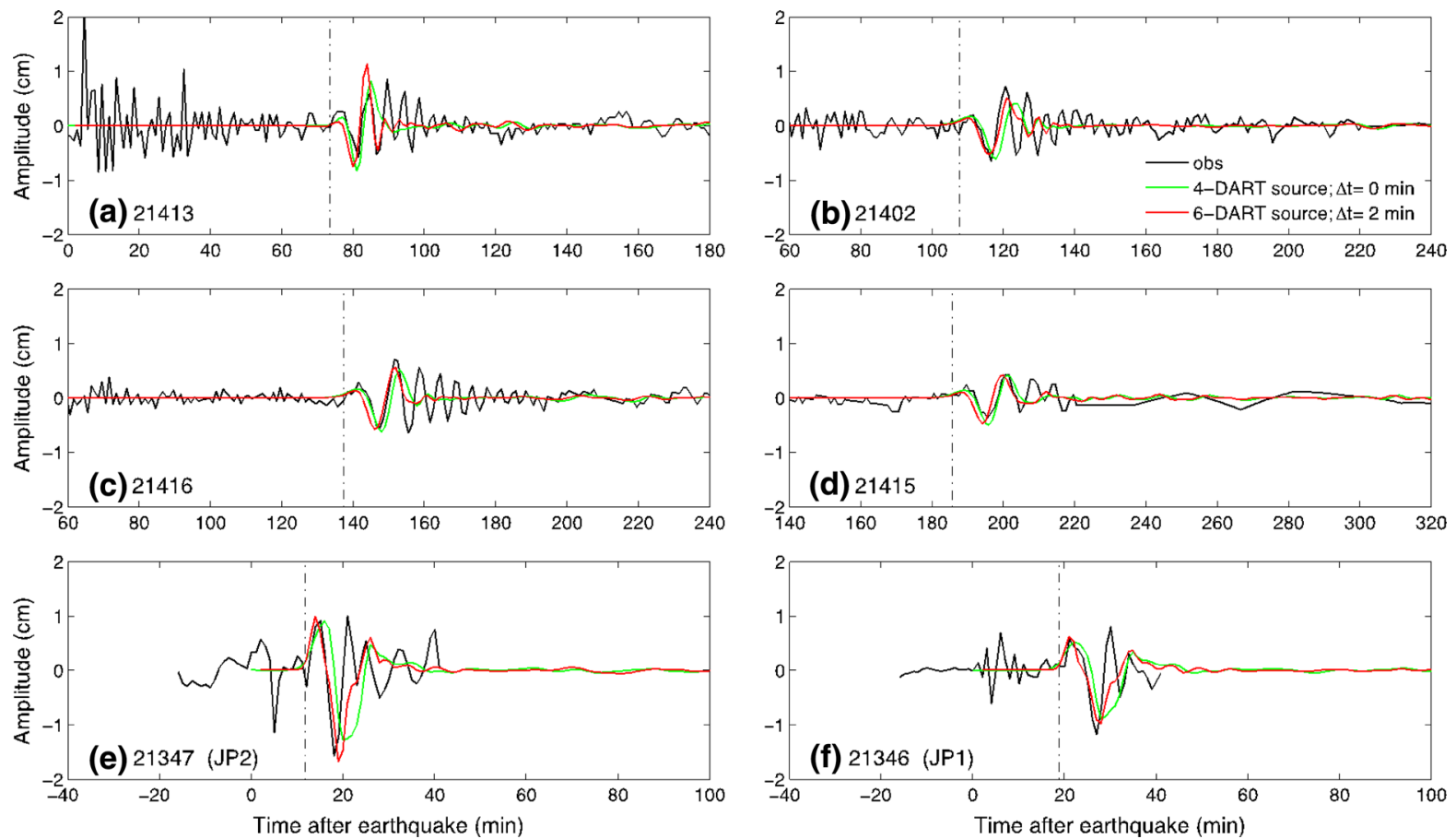

Figure 2

December 7, 2012 tsunami source as derived using two Japanese stations [21347 (JP2) and 21346 (JP1)], three US stations (21413, 21415, 21416) and one Russian station (21402). Black line represents observations. The green line represents the source using only the US and Russian stations (4-DART solution), while the red line represents the source including the additional two Japanese stations (6-DART solution). The red line indicates an improved match with observations at all six stations. The model time series are shifted $\Delta t$ min. Vertical dashed lines represent tsunami arrival time at each DART station, which is estimated from the modeled first wave from the 4-DART source, since the signal to noise ratio of the observation is relatively low

produced the tsunami amplitude time series, represented by the red lines in Fig. 2. The maximum amplitude map is a good proxy for tsunami energy (TANG et al. 2012). Note in Fig. 3 that the tsunami energy distribution was primarily perpendicular to the trench. To the north of the source, the trench along Japan, the Kuril Islands, and the Alaska archipelago served as a wave guide for the tsunami. To the south of the source, DART station 21413 was in a main lobe of energy providing key data on this tsunami. The energy content from each tsunami source was computed using the methodology described in TANG et al. (2012). Using four US and Russian DART data, the energy content was estimated to be $2.86 \times 10^{11} \mathrm{~J}$. Using all six DART stations, the energy content was estimated to be $3.63 \times 10^{11} \mathrm{~J}$ or $27 \%$ more energy.

\section{Near-Field Inundation Model}

Because the tsunami was small (around $1-\mathrm{cm}$ amplitude near the source), the tsunami caused no flooding or damage. The tsunami was measured along Japan's coastline at tide stations providing an opportunity to compare coastal observations with model results. To further evaluate the source of the 7 December 2012 tsunami, both sources (4- and 6-DART inversions) were used as input into tsunami inundation models developed by WEI et al. (2013) for the 2011 Japanese tsunami (see Fig. 4 for coastline covered by the model). Using the WEI et al. (2013) inundation models, results were compared with the Ofunato, Kushiro, and Hanasaki tide gauge observations (see Fig. 4b). The red lines in Fig. $4 \mathrm{~b}$ represent the model results from 6-DART inversion that shows 


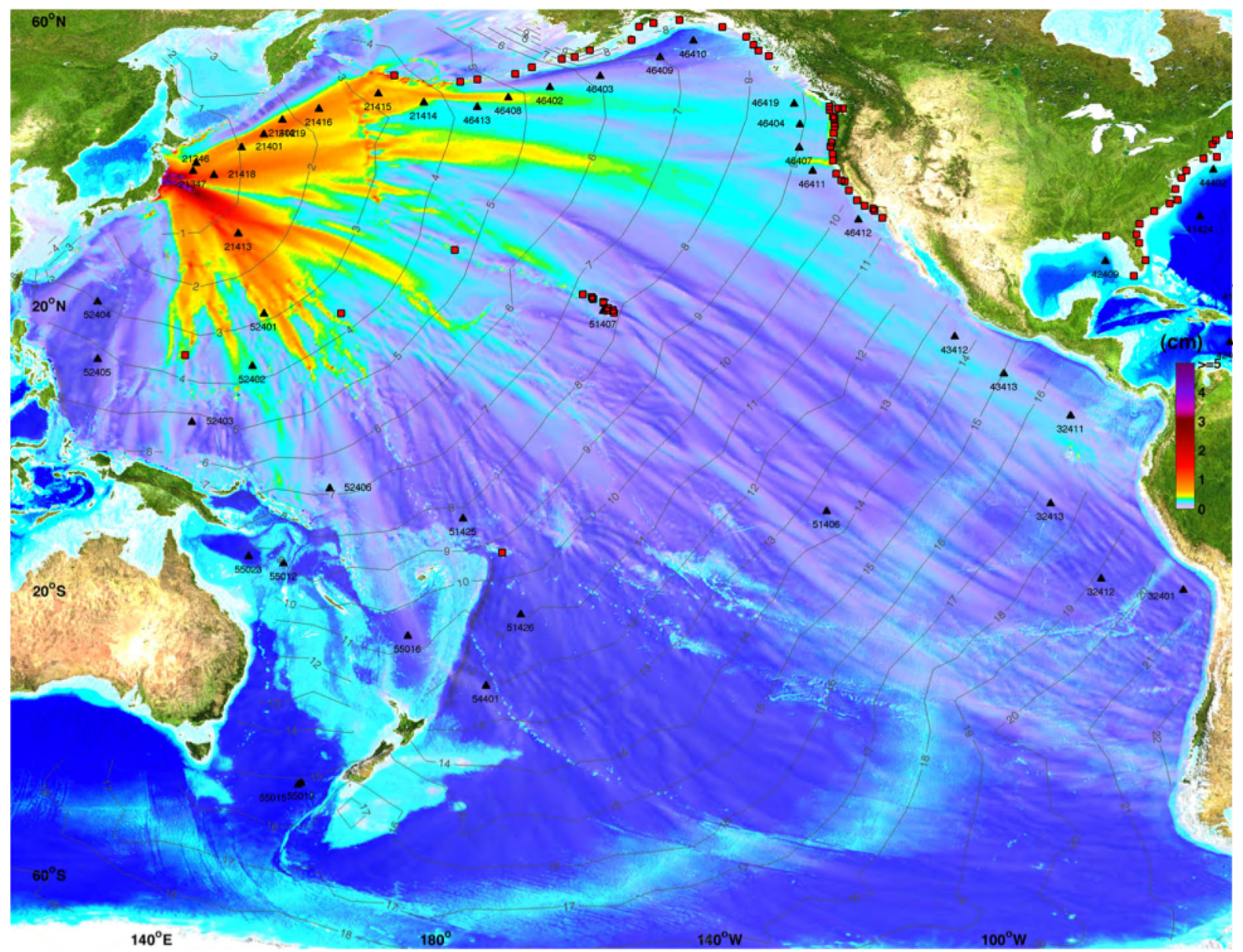

Figure 3

Model maximum offshore amplitude plot from 7 December 2012 Japanese tsunami using six DART stations. Black triangles represent locations of DART stations in the global array. Red boxes are locations of high-resolution inundation models. Contours indicate the travel time in hours

agreement with the tide gauge observations. Comparing to the 6-DART inversion, the 4-DART inversion (green lines in Fig. 4b) gives similar results at the Hanasaki and Kushiro, but differs in arrival time and wave period at the Ofunato. Without introducing an outer-rise unit source, the 4-DART inversion led to an 8-min early arrival time at Ofunato, while the 6-DART inversion provided improved estimate of tsunami arrival time. The model computation compares well with the measurements at Ofunato, which were mainly due to the northern rupture of the earthquake (see Fig. 4a). The spectrum analysis in Fig. 4c indicates that the model reproduced two dominant wave periods (approximately 4 and $10 \mathrm{~min}$ ) recorded at Ofunato station, with slight overestimation for the $10 \mathrm{~min}$ wave period. The 4 and 10-min waves appear within the first $2 \mathrm{~h}$ after the earthquake, and are more related to the tsunami source itself. However, the 40- and 50-min wave period may be a result of local wave system near Japan's east coast. The spectral comparison between model and measurements in Fig. 4c (Hanasaki) also shows similar phenomenon. At Hanasaki, the model indicates the dominant wave period induced by the tsunami wave is about 16-20 min, agreeing well with measurements. At Kushiro, the measurements are dominated by waves of 30- to 70-min period, which can be clearly visualized in the time series 
(a)
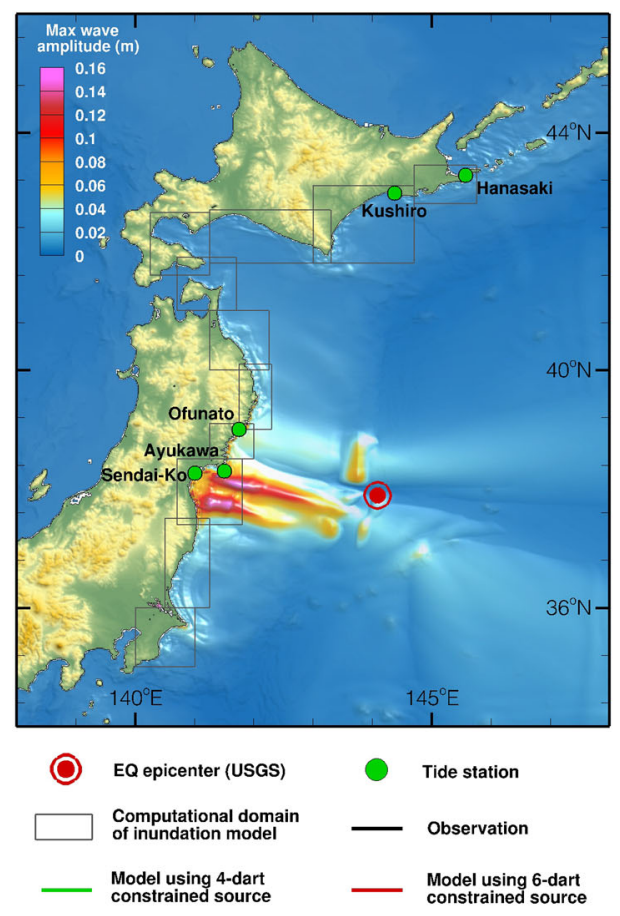

(b)
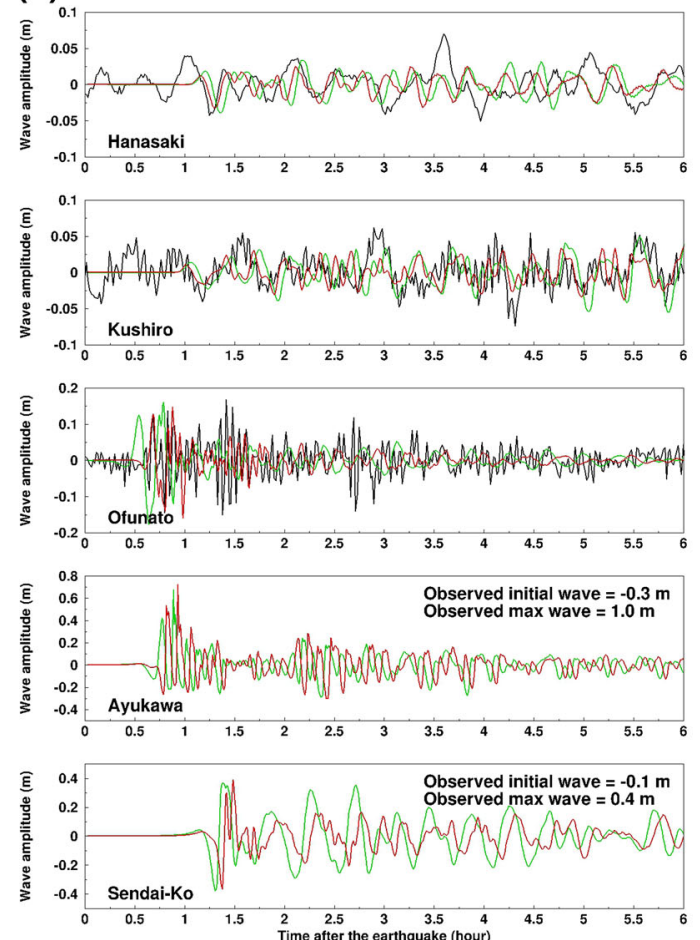

(c)
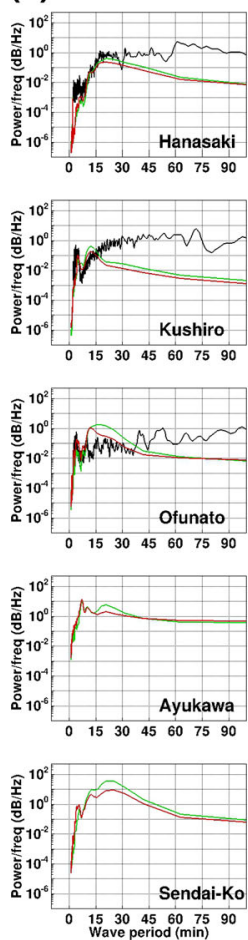

Figure 4

a Model setup. The grey rectangles represent the coverage of WEI et al. (2013) models; the green dots indicate the tide gauge locations; and dot within a circle is the USGS epicenter of the December 7, 2013 earthquake. b Comparison of results using the 4-dart and 6-DART sources at five tide gauge stations (green dots in a), and with observation at three tide gauge stations. In the tsunami time series, the black line represents observations, while the red line (6-DART solution) and green line (4-DART solution) represents model output at the same location.

c Spectrum analysis of observed and computed time series at five tide gauge stations

comparison (Fig. 4b) before tsunami arrived. Computational results at Kushiro show the tsunami has two dominant wave periods, 5 and 13 min.

During the 7 December 2012 event, JMA's tsunami information bulletin No. 8 described the recorded wave amplitudes (initial and maximum) at Ayukawa and Sendai-Ko tide stations (the time series of observation at Ayukawa and Sendai-Ko are not available for us to be used in this study). The bulletin reported the initial waves were both depressions, -0.3 and $-0.1 \mathrm{~m}$ at Ayukawa and Sendai-Ko, respectively. Our model computation at these two locations (Fig. 4b) fits well with the observations, although the amplitude of the depression is slightly larger than recorded at Sendai-Ko. The model results indicate that the maximum tsunami amplitude near Ayukawa is $>0.7 \mathrm{~m}$, and $0.4 \mathrm{~m}$ at Sendai-Ko, which both agree with the reported values, $1 \mathrm{~m}$ at Ayukawa and $0.4 \mathrm{~m}$ at Sendai-Ko. These results further validate the tsunami energy projection shown in Fig. $4 \mathrm{a}$ that the highest tsunami waves are focusing on the coastline of Sendai Bay between Soma and Ayukawa. More interestingly, the focusing and bifurcation of the tsunami energy towards Sendai Bay (Fig. 4a) can be attributed to an interaction of two factors: the tsunami energy focusing from a strip source (KÂNO$\breve{G L U}$ et al. 2013), and the energy focusing and bifurcation caused by bathymetric features over the continental shelf. These results highlight the value of obtaining the correct source estimate from offshore tsunami measurements.

It is worth noting that all of our model results for tide gage comparison were extracted from offshore points close to the tide gage locations. Due to the lack of accurate tide gage coordinates, the model might underestimate the wave amplitudes recorded at the 
tide gages. The lack of accurate bathymetric and topographic data can also affect the modeling results, since many coastal structures near tide gages, such as breakwaters and seawalls, are not reflected in the 50-m resolution model (WEI et al. 2013).

Hence, we are able to conclude that the two Japanese DART stations performed as designed during a tsunami and improved the accuracy of the tsunami source. The more accurate tsunami source led to more accurate model simulations of tsunami dynamics along Japan's coastlines.

\section{Discussion}

\subsection{Our Analysis Leads Us to Two Important Findings}

\subsubsection{Improvements in Tsunami Forecast Accuracy in the Near and Far-Fields}

The two recently deployed Japanese DART stations provided data that improved tsunami forecasting in the near and far-fields. Near-field improvements can be seen in Fig. 4 where the tsunami amplitude time series (represented by red lines) shows a better agreement to the observations at three tide gauges. Specifically at Ofunato, the shorter wave period of the model amplitude time series and the $15 \mathrm{~cm}$ maximum amplitude and $15 \mathrm{~cm}$ maximum drawdown serve as an accurate forecast of maximum and minimum amplitude range. The model results, however, did not simulate well the second tsunami packet that arrived about $1 \mathrm{~h}$ after the first energy packet. Improvements can also be seen in Fig. 2 in model simulations at the six DART stations that recorded the tsunami. For the two Japanese DART stations, one can see a better agreement between model results and observations at DART JP2 and JP1. Specifically, the 6-DART derived source, represented by the amplitude time series (red line), has a a shorter wave period that matches the observations of the first tsunami wave at these two stations. This shorterperiod wave also improves the match with observations at the far-field DARTs, namely 21413, 21415, 21416, and 21402. At 21416 and 21402, northwest of the tsunami source location, the amplitude time series (red line) agrees well with the observed amplitudes of the initial wave. However, at the southernmost DART station, 21413, the amplitude agreement is not as good. Overall, the 6-DART source provides a better simulation of the observed tsunami time series at six different DART stations and at least one coastal tide gauge. The 6-DART source contained $27 \%$ more energy than the 4-DART source, and using this source provided better model agreement with observations at five tide gauges.

\subsubsection{Reduced Detection Time Leads to a Faster Assessment of the Tsunami's Destructive Power}

The greatest benefit of the recently deployed Japanese DART stations was the close proximity to the tsunami source. The locations of JP2 and JP1 enabled the detection of the 7 December 2012 Japanese tsunami 11-20 min after generation. The fact that the tsunami was only $1.0 \mathrm{~cm}$ in amplitude at DART JP2 meant that no destructive tsunami had been generated. In Fig. 1, which illustrates the comparison between the devastating 2011 and the non-destructive 2012 tsunamis, the tsunami amplitude at DART station 21413 in 2011 was measured to be $78 \mathrm{~cm}$, or nearly 80 times the amplitude the 2012 tsunami. Five minutes later, the $0.5 \mathrm{~cm}$ amplitude tsunami was detected at DART station JP1, confirming that no destructive tsunami was approaching Japan's coastline.

At 08:51:46 UTC (33 min after the earthquake origin time) JMA had a full tsunami waveform from JP2 as shown in the red line of the lower left panel of Fig. 2. At 08:52:46 UTC (34 min after the earthquake origin time), JMA had a full tsunami waveform from JP1 as shown in the red line of the lower right panel of Fig. 2. Visual analysis of these waveforms would have confirmed that the 7 December 2012 tsunami was not destructive and posed no flooding hazard to Japan's coastline. Since the tsunami arrived at the Ofunato tide gauge $40 \mathrm{~min}$ after the earthquake origin time, an accurate forecast could have been provided between 7 and 23 min before the tsunami's arrival at Ofunato. Such fast, accurate assessments of tsunami danger are the foundation blocks in building confidence in tsunami warning accuracy. 
The 7 December 2012 tsunami has provided a good test of the tsunami mode performance for the newly deployed Japanese DART stations JP1 and JP2. The bottom pressure sensor worked within stated accuracy while the tsunami reporting mode worked properly in acquiring and sending near realtime data to JMA within the designed time frames. Data from DART stations JP1 and JP2 have been analyzed within the NOAA forecast system and found to be working properly for tsunami forecast and warning applications. The Japanese data from DART stations JP1 and JP2 improved the accuracy of the tsunami source derived from the NOAA forecast system. This more accurate source was used to improve forecast accuracy at coastal tide gauge in Ofunato, Japan. The inclusion of DART stations JP1 and JP2 into the JMA tsunami warning system will improve tsunami forecast speed and accuracy.

\subsection{Future Opportunities}

The addition of two deep-water tsunami detectors by Japan to the global network of DART stations (see Fig. 3, black triangles) is an excellent example of international cooperation among tsunami threatened nations. By sharing data from these two Japanese DART stations, the Pacific coastal nations benefit from faster detection of tsunamis and more accurate forecasts. Further, the tsunami research community benefits from more data available immediately following tsunami generation. We encourage other nations to follow the leads of Australia, Chile, India, Japan, Russia, Thailand, and the United States in deploying DART stations off their coastlines and sharing their data with all nations. Such international cooperation leads to faster and more accurate tsunami warnings, which, in turn, save lives from the destructive power of tsunamis.

\section{Acknowledgments}

We thank Rob Lawson of SAIC for providing $15 \mathrm{~s}$ data from DART stations 21436 (JP1) and 21437 (JP2); Michael Spillane and Jean C. Newman for assistance with the propagation database. We are grateful for UNESCO and IOC sea level station monitoring facility (http://www.ioc-sealevelmonit oring.org/) that provide access to the tide gage data along Japan's coastline. We also acknowledge the hard work of JMA, Toho Mercantile, and Oyo Corporation for initiating and completing the purchase of DART stations 21436 and 21437. Special acknowledgement goes to the SAIC deployment team who successfully deployed two DART buoys in the hostile, dangerous, November seas off Japan's coastline. This publication was (partially) funded by the Joint Institute for the Study of the Atmosphere and Ocean (JISAO) under NOAA Cooperative Agreement No. NA10OAR4320148, Contribution No. 2116; PMEL Contribution 4009.

Open Access This article is distributed under the terms of the Creative Commons Attribution License which permits any use, distribution, and reproduction in any medium, provided the original author(s) and the source are credited.

\section{REFERENCES}

Beavan, J., X. Wang, C. Holden, K. Wilson, K. Power, G. Prasetya, M. Bevis, and R. Kautoke, (2010), Near-simultaneous great earthquakes at Tongan megathrust and outer rise in September 2009, Nature, 466, 959-963.

Calais, E., A. Freed, G. Mattioli, F. Amelung, S. Jónsson, P. Jasma, S.-H. Hong, T. Dixon, C. Prépetit, R. Momplaisir (2011), Transpressional rupture of an unmapped fault during the 2010 Haiti earthquake, Nature Geoscience, 3(11), 794-799.

Grilli, S.T., J. Harris, Tappin, D.R., Masterlark, J.T. Kirby, F. SHI and G. MA (2012), Modeling of the Tohoku-oki 2011 tsunami coastal hazard: effects of a mixed co-seismic and seabed failure source, EOS Trans. AGU, 93(52), Fall Meet. Suppl., Abstract NH42A-06.

Hayes, G.P., R.W. Briggs, A. Sladen, E.J. Fielding, C. Prentice, K. Hudnut, P. Mann, F.W. TAYlor, A.J. Crone, R. Gold, T. Ito, and M. Simmons (2011), Complex rupture during the 12 January 2010 Haiti earthquake, Nature Geoscience, 3(11):800-805.

KÂnoĞLu U., V.V. Titov, B. Aydin, C. Moore, T.S. Stefanakis, H. Zhou, M. Spillane, C.E. Synolakis (2013), Focusing of long waves with finite crest over constant depth, Proc R Soc A 20130015. http://dx.doi.org/10.1098/rspa.2013.0015.

Lay, T., C.J. Ammon, H. Kanamori, L. Rivera, K.D. Koper and A.R. Hutкo (2010), The 2009 Samoa-Tonga great earthquake triggered doublet, Nature, 466, 964-968, doi:10.1038/ nature09214.

Synolakis, C.E., Bernard, E.N., Titov, V.V., Kanoglu, U., and GonZalEZ, F. (2008), Validation and verification of tsunami numerical models. Pure and Applied Geophysics 165(11-12), 2197-2228. doi:10.1007/s00024-004-0427-y.

Tang, L., V.V. Titov, E. Bernard, Y. Wei, C. Chamberlin, J.C. Newman, H. Mofjeld, D. Arcas, M. Eble, C. Moore, B. Uslu, C. Pells, M.C. Spillane, L.M. Wright, and E. Gica (2012), Direct 
energy estimation of the 2011 Japan tsunami using deep-ocean pressure measurements, J. Geophys. Res., 117, C08008, doi:10. 1029/2011JC007635.

Titov, V.V. (2009), Tsunami forecasting, Chapter 12 in The Sea, Volume 15: Tsunamis, Harvard University Press, Cambridge, MA and London, England, 371-400.

Wei, Y., E.N. Bernard, L. Tang, R. Weiss, V.V. Titov, C. Moore, M. Spillane, M. Hopkins and U. KÂnoĞLu (2008), Real-time experimental forecast of the Peruvian tsunami of August 2007 for U.S. coastlines, Geophys. Res. Lett. 35, L04609, doi:10.1029/ 2007GL032250.

Wei, Y., C. Chamberlin, V.V. Titov, L. Tang, and E.N. Bernard (2013), Modeling of 2011 Japan Tsunami-lessons for near-field forecast, Pure Appl. Geophys., 170, 1309-1331, doi:10.1007/ s00024-012-0519-z.

(Received April 8, 2013, revised August 3, 2013, accepted September 24, 2013, Published online October 23, 2013) 